\title{
Interaction of functional gastrointestinal disorders with postpartum conditions related to mother and baby
}

\author{
Özlem Bekem ${ }^{1 \oplus}$, İlker Günay ${ }^{2 \oplus}$, Filiz Çelik ${ }^{2 \oplus}$, Hurşit Apa ${ }^{2 \oplus}$ \\ ${ }^{1}$ Division of Pediatric Gastroenterology, Hepatology and Nutrition, ${ }^{2}$ Department of Pediatrics, Health Sciences University, Dr. Behcet \\ Uz Children's Hospital, İmir, Turkey.
}

\begin{abstract}
Background. Functional gastrointestinal disorders (FGID) may affect or may be affected by postpartum depression (PPD), mode of feeding and postpartum life quality. We aimed to evaluate the interaction between FGID and these parameters in infants.

Methods. The study group consisted of babies attending our outpatient clinics. There were three age groups: 4-6 weeks, 3-4 months and 6-7 months. Demographic data of the babies and mothers, and data of feeding were collected. For the diagnosis of FGID, Rome III criteria were used. Mothers were screened with the Edinburgh Depression Scale. Quality of life (QoL) scores were obtained by using the "Maternal Postpartum Quality of Life Questionnaire". Factors affecting the presence of FGID, PPD and quality of life were analyzed.

Results. Two hundred thirteen infants were enrolled during the study period. FGID was present with similar rates in both genders and was lower $(31.5 \%)$ in the 6-7 month-old group $(\mathrm{p}=0.001)$. Infantile colic was higher in girls $(68.6 \%$ vs. $31.4 \%$, $\mathrm{p}=0.016)$. In 4-6 week-old infants with infantile dyschesia, the delivery route was mostly cesarean $(83.3 \%$ vs. 16.7\%, p=0.006). Similarly, regurgitation was more frequent in 6-7 month-old infants born by cesarean $(88.9 \%$ vs. $11.1 \%, p=0.035)$, and was more frequent in infants being exclusively breastfed $(60.9 \%$, $\mathrm{p}=0.037)$. QoL scores were lower in mothers with depression (20.9 \pm 3.4 vs. 23.9 $\pm 3.6, \mathrm{p}=0.003)$. Infantile colic was higher in mothers with depression, but not significantly (29.3\% vs. $11.4 \%, \mathrm{p}=0.057)$.
\end{abstract}

Conclusions. Caesarian section delivery and breastfeeding were influential on infantile dyschesia and regurgitation subgroups. No other studied factor seemed to affect FGID.

Key words: functional gastrointestinal disorders, infants, breastfeeding, postpartum depression, life quality.

Functional gastrointestinal disorders (FGID) in infants are chronic or recurrent symptoms that are age-dependent, and cannot be explained by structural or biochemical problems. Regurgitation, rumination syndrome, cyclic vomiting syndrome, infantile colic, functional diarrhea, infant dyschesia and functional constipation are defined under this group of disorders. These symptoms may be a

$凶$ Özlem Bekem

obekem@yahoo.com

Received 5th June 2020, revised 30th July 2020,

11st November 2020, accepted 15th November 2020.

This study was presented at the 12th Pediatric Gastroenterology, Hepatology and Nutrition Congress, İzmir, Turkey, April 18-21, 2018. component of normal development or an inappropriate response to different stimuli. ${ }^{1}$ Biopsychosocial model is commonly accepted to explain the etiology of FGID. ${ }^{2}$ In this model genetics, environment, life stress, psychological state, coping, social support, motility and gut hypersensitivity have reciprocal interaction with symptoms. ${ }^{2}$ The effect of parent's psychological state and behaviors are emphasized in many studies. ${ }^{3,4}$ These studies are mostly performed in older children. During infancy, some conditions like postpartum depression (PPD), mode of feeding, postpartum life quality may affect or may be affected by FGID.

PPD is an important, frequent and chronic problem if untreated. ${ }^{5}$ It affects $9.1-19.2 \%$ of mothers in the first months after birth. ${ }^{6,7}$ Stressful 
life events, poor social support, infant health problems, low income and education, previous history of depression are risk factors for PPD. ${ }^{8}$ It has been shown that PPD lowers life quality significantly. Mothers with PPD displayed lower quality of life (QoL) scores especially in emotional well-being, mostly at the $2^{\text {nd }}$ and $4^{\text {th }}$ months postpartum. ${ }^{9}$ This situation may affect the whole family along with the mother in psychological and physical ways. For example, maternal PPD and attachment problems of the mother and the baby are suggested as reasons for infantile colic. ${ }^{10-13}$ However, no data is present with regard to PPD and other infant FGID.

Diet is an important factor in FGID etiopathogenesis. Symptoms are reported to be food-related in most of the children with FGID. ${ }^{14}$ Consuming foods like milk, spicy foods, pizza, sodas, fried foods and fast foods may exacerbate the symptoms of FGID in older children. ${ }^{15,16}$ This may be explained by foods' ability to alter gut motility, sensitivity and microbiota. ${ }^{14}$ There may be a similar effect in FGID of infants. The relationship between infantile colic and breastfeeding is well studied. In these studies, it has been demonstrated that exclusive breastfeeding reduces infantile colic. ${ }^{17,18}$ However its effect is not clear in other FGID.

FGID do not only affect the infant's health but also the emotional status and daily life of the family. Parents miss workdays and have less ability to concentrate at work. ${ }^{19}$ Infantile colic lowers QoL scores of mothers, especially in physical and social functioning domains. ${ }^{20}$ However, data concerning the effects of other FGID on life quality is scarce.

In this study, we aimed to evaluate the interaction between FGID, PPD, maternal quality of life and breastfeeding in infants.

\section{Material and Methods}

This study was designed as a cross-sectional study. The study group was selected from three outpatient clinics (pediatric gastroenterology, social pediatrics, general pediatrics). The sample size for a CI level of $95 \%$ and $80 \%$ power was calculated to be 189 children with regard to infantile FGID incidence of $77 \%{ }^{21-24}$ Considering a $10 \%$ sample loss we decided to have a sample size of 200. Data was collected between February and December 2013.

We had three age groups for the sample: infants between 4-6 weeks, 3-4 months and 6-7 months. We aimed to study children under 6 months as this age is the limit for exclusive breastfeeding. The 4-6-week-old group was chosen as this age is the only appropriate time to perform the maternal postpartum QoL scale..$^{25}$ As PPD is highest at 3 months after birth we chose 3-4 months old as the second group. ${ }^{26}$ All children within the age range of groups were considered for the sample. The questionnaires were filled at the first visit, if a baby was admitted more than once they were not reenrolled to the study for older age groups. Exclusion criteria were severe conditions that require urgent intervention, chronic illnesses and babies brought to the hospital without their mother. Organic diseases presenting like FGID were excluded via history, physical examination and absence of alarm signs.

Demographic data collected for the babies were age (in months), sex, birth weight (as appropriate for gestation or small for gestation), socioeconomic status (SES) (low, intermediate, high) and family type. SES was grouped using a classification developed by Nesanir and Eser. ${ }^{27}$ This classification uses the maternal level of education and the occupation of the father. Family types were classified as nuclear or extended. Variables related to the mother and birth were maternal age (in years), maternal education level, type of delivery (caesarian (c) section or vaginal), presence of miscarriages (absent or present) and parity (first or multiple). According to education level, mothers were divided into three groups. First group was illiterate and literate but did not finish elementary school; second group was consisted of elementary school graduates and 
the last group was for women who graduated from secondary school or higher. ${ }^{27}$ We also collected data on feeding. These were; type (breast milk or other) and time (within $1^{\text {st }}$ hour, after $1^{\text {st }}$ hour within $1^{\text {st }}$ day, later than $1^{\text {st }}$ day) of the first feeding following birth, the current type of feeding (breastfeeding, mixed or nonbreastfeeding), presence of breastfeeding problems and use of bottle and/or pacifiers. Any problem interfering with breastfeeding like fissures of areolas, rejection of breastfeeding was included under this title. We asked an openended question concerning how well mother and baby were coping with breastfeeding. Anything declared as a problem by the mothers was noted as a breastfeeding problem.

Rome III criteria were used for FGID diagnosis. ${ }^{1}$ Emotional status of the mother was screened with Edinburgh Depression Scale validated for Turkish. ${ }^{28}$ Cut-off score for PPD was set as 10 points as recommended by the original scale. ${ }^{29}$ Mothers were referred for the evaluation of depression if their score was above 10. QoL scores were obtained by using the "Maternal Postpartum Quality of Life Questionnaire", which is validated for Turkish. ${ }^{25}$ The scale was scored between 0-30. Higher scores demonstrated a better life quality. This scale was given only to the mothers in the 4-6-week-old baby group as this was the age recommended by the authors. ${ }^{25}$

Statistical analysis was done by using SPSS software. Mean values were given as mean+/standard deviation. When the distribution of the groups was not normal, Mann-Whitney U and variance analysis were used. Chi-square and t-test were used where distribution was normal to analyze factors affecting the presence of FGID, PPD and low scores on quality of life scores. $P$ value $<0.05$ was accepted as significant. Ethics Committee approval was obtained from Dr. Behcet Uz Children's Ethics Committee (B-10-4-ISM-4-35-65-72, 28.02.2013). Informed consent was taken from all parents.

\section{Results}

Two hundred thirteen infants were enrolled during the study period. Of the study group, $108(50.7 \%)$ were male. Children were grouped as follows; $4-6$ weeks old ( $\mathrm{n}=61,28.6 \%), 3-4$ months old $(\mathrm{n}=85,39.9 \%)$ and 6-7 months old $(n=67,31.5 \%)$. The mean age of the mothers was $27.7 \pm 5.2$ years. More than half of the mothers $(\mathrm{n}=116,54.5 \%)$ had multiple parities, and $45(21.1 \%)$ had a history of miscarriage. The mode of delivery was C-section in 120 (56.6\%) mothers. Generally, babies had birth weights appropriate for gestational age $(n=203,96.2 \%)$. All the infants were born full term. Most $(n=166$, $78 \%$ ) of the families were of intermediate socioeconomic status. Thirty-two (15\%) families had high and 15 (7\%) had low socioeconomic status. Approximately half of the mothers $(\mathrm{n}=116,54.5 \%)$ had graduated from secondary school or above, while $17(8.0 \%)$ were illiterate or literate but did not finish elementary school. Most of the babies ( $n=133,62.3 \%$ ) within six months were exclusively breastfed. In the babies older than six months $79.1 \%$ were still breastfed besides complementary feeding. Breast milk was the first food given to 165 (77.5\%) babies. The first breastfeeding was performed in the first hour of birth in 122 (57.5\%) and on the first day of birth in the other 67 (31.6\%) babies. One baby was not breastfed at all. A breastfeeding problem was present in $70(33.3 \%)$ mothers. Pacifier/bottle usage rate was high in our study group ( $\mathrm{n}=150,70.8 \%)$. The demographic data are given in Table I.

A FGID was present in $44.1 \%$. The most common FGID was regurgitation (21.6\%), infantile colic $(16.4 \%)$ and infantile dyschesia (11.7\%). Two babies $(0.9 \%)$ had infant rumination syndrome, one baby $(0,5 \%)$ had cyclic vomiting syndrome, six babies $(2.8 \%)$ had functional constipation and none had functional diarrhea. FGID was present with a similar rate in both genders $(\mathrm{p}=0.492)$, and with a lower rate $(13.8 \%)$ in the 6-7 month-old group $(\mathrm{p}=0.001)$ (Table I). 
Table I. Demographic data of the children.

\begin{tabular}{|c|c|c|c|c|c|c|}
\hline & Total group & Postpartu & lepression & $\begin{array}{l}\text { Quality of } \\
\text { life score }\end{array}$ & & \\
\hline & & Present & Absent & & Present & Absent \\
\hline Gender & $\mathrm{n}=213$ & $\mathrm{n}=99$ & $\mathrm{n}=114$ & $\mathrm{n}=53$ & $\mathrm{n}=94$ & $\mathrm{n}=119$ \\
\hline Female & $49.3 \%$ & $47.5 \%$ & $50.9 \%$ & $23.0 \pm 4.5$ & $46.7 \%$ & $53.3 \%$ \\
\hline Male & $50.7 \%$ & $52.5 \%$ & $49.1 \%$ & $22.4 \pm 3.2$ & $41.7 \%$ & $58.3 \%$ \\
\hline Age groups & $n=213$ & $\mathrm{n}=99$ & $\mathrm{n}=114$ & $\mathrm{n}=53$ & $\mathrm{n}=94^{*}$ & $\mathrm{n}=119^{*}$ \\
\hline 4-6 weeks & $28.6 \%$ & $25.3 \%$ & $31.6 \%$ & $22.7 \pm 3.8$ & $31.9 \%$ & $26.0 \%$ \\
\hline 3-4 months & $39.9 \%$ & $41.4 \%$ & $38.6 \%$ & - & $54.3 \%$ & $28.6 \%$ \\
\hline 6-7 months & $31.5 \%$ & $33.3 \%$ & $29.8 \%$ & - & $13.8 \%$ & $45.4 \%$ \\
\hline Miscarriage & $n=213$ & $\mathrm{n}=99$ & $\mathrm{n}=114$ & $\mathrm{n}=53$ & $\mathrm{n}=94$ & $\mathrm{n}=119$ \\
\hline Present & $21.1 \%$ & $20.2 \%$ & $21.9 \%$ & $21.8 \pm 4.2$ & $18.1 \%$ & $23.5 \%$ \\
\hline Absent & $78.9 \%$ & $79.8 \%$ & $78.1 \%$ & $22.9 \pm 3.7$ & $81.9 \%$ & $76.5 \%$ \\
\hline Parity & $\mathrm{n}=213$ & $\mathrm{n}=99$ & $\mathrm{n}=114$ & $\mathrm{n}=53$ & $\mathrm{n}=94$ & $\mathrm{n}=119$ \\
\hline One & $45.5 \%$ & $43.4 \%$ & $47.4 \%$ & $23.1 \pm 3.8$ & $48.9 \%$ & $42.9 \%$ \\
\hline Multiple & $54.5 \%$ & $56.6 \%$ & $52.6 \%$ & $22.3 \pm 3.8$ & $51.1 \%$ & $57.1 \%$ \\
\hline Birth weight & $\mathrm{n}=211$ & $\mathrm{n}=99$ & $\mathrm{n}=112$ & $\mathrm{n}=52$ & $\mathrm{n}=93$ & $\mathrm{n}=118$ \\
\hline AGA & $96.2 \%$ & $96.4 \%$ & $96.0 \%$ & $22.7 \pm 3.9$ & $96.8 \%$ & $95.8 \%$ \\
\hline SGA & $3.8 \%$ & $3.6 \%$ & $4.0 \%$ & $21.2 \pm 0.0$ & $3.2 \%$ & $4.2 \%$ \\
\hline Mode of delivery & $\mathrm{n}=212$ & $\mathrm{n}=99$ & $\mathrm{n}=113$ & $\mathrm{n}=53$ & $\mathrm{n}=93$ & $\mathrm{n}=119$ \\
\hline $\mathrm{c} / \mathrm{s}$ & $56.6 \%$ & $52.5 \%$ & $60.2 \%$ & $22.8 \pm 3.1$ & $59.1 \%$ & $54.6 \%$ \\
\hline Vaginally & $43.4 \%$ & $47.5 \%$ & $39.8 \%$ & $22.5 \pm 4.6$ & $40.9 \%$ & $45.4 \%$ \\
\hline Maternal age groups & $\mathrm{n}=213$ & $\mathrm{n}=99$ & $\mathrm{n}=114$ & $\mathrm{n}=53$ & $\mathrm{n}=94$ & $\mathrm{n}=119$ \\
\hline$\leq 18$ years & $1.9 \%$ & $2.0 \%$ & $1.8 \%$ & $22.0 \pm 0.0$ & $2.1 \%$ & $1.7 \%$ \\
\hline 19-35 years & $90.6 \%$ & $90.9 \%$ & $90.4 \%$ & $22.5 \pm 3.7$ & $89.4 \%$ & $91.6 \%$ \\
\hline$>35$ years & $7.5 \%$ & $7.1 \%$ & $7.8 \%$ & $24.8 \pm 5.5$ & $8.5 \%$ & $6.7 \%$ \\
\hline Maternal education level & $n=213$ & $\mathrm{n}=99^{*}$ & $\mathrm{n}=114^{*}$ & $\mathrm{n}=53$ & $\mathrm{n}=94$ & $\mathrm{n}=119$ \\
\hline Illiterate/literate & $8.0 \%$ & $3.0 \%$ & $12.3 \%$ & $21.2 \pm 0.8$ & $10.6 \%$ & $5.9 \%$ \\
\hline Elementary school & $37.5 \%$ & $39.4 \%$ & $36.0 \%$ & $23.7 \pm 4.0$ & $31.9 \%$ & $42.0 \%$ \\
\hline Secondary school or above & $54.5 \%$ & $57.6 \%$ & $51.7 \%$ & $22.4 \pm 3.9$ & $57.5 \%$ & $52.1 \%$ \\
\hline Socioeconomic status & $\mathrm{n}=213$ & $\mathrm{n}=99^{*}$ & $\mathrm{n}=114^{*}$ & $\mathrm{n}=53$ & $\mathrm{n}=94$ & $\mathrm{n}=119$ \\
\hline Low & $7.0 \%$ & $2.0 \%$ & $11.4 \%$ & $21.2 \pm 0.8$ & $10.6 \%$ & $4.2 \%$ \\
\hline Intermediate & $77.9 \%$ & $78.8 \%$ & $77.2 \%$ & $23.0 \pm 4.0$ & $75.6 \%$ & $79.8 \%$ \\
\hline High & $15.0 \%$ & $19.2 \%$ & $11.4 \%$ & $22.4 \pm 4.0$ & $13.8 \%$ & $16.0 \%$ \\
\hline Nuclear family & $n=213$ & $\mathrm{n}=99$ & $\mathrm{n}=114$ & $\mathrm{n}=53$ & $\mathrm{n}=94$ & $\mathrm{n}=119$ \\
\hline Yes & $83.1 \%$ & $86.9 \%$ & $79.8 \%$ & $22.7 \pm 3.6$ & $81.9 \%$ & $84.0 \%$ \\
\hline No & $16.9 \%$ & $13.1 \%$ & $20.2 \%$ & $22.4 \pm 5.0$ & $18.1 \%$ & $16.0 \%$ \\
\hline First consumed food at birth & $n=213$ & $\mathrm{n}=99$ & $\mathrm{n}=114$ & $\mathrm{n}=53$ & $\mathrm{n}=94$ & $\mathrm{n}=119$ \\
\hline Breast milk & $77.5 \%$ & $80.8 \%$ & $74.6 \%$ & $22.6 \pm 4.0$ & $79.8 \%$ & $75.6 \%$ \\
\hline Other & $22.5 \%$ & $19.2 \%$ & $25.4 \%$ & $23.1 \pm 2.2$ & $20.2 \%$ & $24.4 \%$ \\
\hline
\end{tabular}

${ }^{*} \mathrm{p}<0.05$

AGA: appropriate for gestational age, SGA: small for gestational age FGID: functional gastrointestinal disorders, c/s: cesarean section 
Table I. Continued.

\begin{tabular}{lcccccc}
\hline & Total group & Postpartum depression & $\begin{array}{c}\text { Quality of } \\
\text { life score }\end{array}$ & \multicolumn{2}{c}{ FGID } \\
\cline { 2 - 7 } & & Present & Absent & & Present & Absent \\
\hline First breastfeeding time & $\mathrm{n}=212$ & $\mathrm{n}=98$ & $\mathrm{n}=113$ & $\mathrm{n}=53$ & $\mathrm{n}=93$ & $\mathrm{n}=118$ \\
$1^{\text {st }}$ hour & $57.5 \%$ & $54.1 \%$ & $61.1 \%$ & $22.8 \pm 4.3$ & $50.6 \%$ & $63.6 \%$ \\
$1^{\text {st day }}$ & $31.6 \%$ & $35.7 \%$ & $28.3 \%$ & $22.5 \pm 3.3$ & $37.6 \%$ & $27.1 \%$ \\
$\quad$ Later than 1 $1^{\text {st }}$ day & $10.4 \%$ & $10.2 \%$ & $10.6 \%$ & $22.9 \pm 2.9$ & $11.8 \%$ & $9.3 \%$ \\
Feeding type & $\mathrm{n}=212$ & $\mathrm{n}=99$ & $\mathrm{n}=113$ & $\mathrm{n}=52$ & $\mathrm{n}=93 *$ & $\mathrm{n}=119 *$ \\
Breastfeeding & $44.4 \%$ & $37.4 \%$ & $50.5 \%$ & $22.5 \pm 4.3$ & $54.8 \%$ & $36.1 \%$ \\
Non-breastfeeding & $10.8 \%$ & $12.1 \%$ & $9.7 \%$ & - & $7.5 \%$ & $13.4 \%$ \\
Mixed & $44.8 \%$ & $50.5 \%$ & $39.8 \%$ & $23.0 \pm 3.2$ & $37.6 \%$ & $50.4 \%$ \\
Breastfeeding problem & $\mathrm{n}=210$ & $\mathrm{n}=98$ & $\mathrm{n}=112$ & $\mathrm{n}=52$ & $\mathrm{n}=93$ & $\mathrm{n}=117$ \\
Present & $33.3 \%$ & $38.8 \%$ & $28.6 \%$ & $22.2 \pm 3.3$ & $29.0 \%$ & $36.8 \%$ \\
Absent & $66.7 \%$ & $61.2 \%$ & $71.4 \%$ & $22.9 \pm 4.0$ & $71.0 \%$ & $63.2 \%$ \\
Pacifier/bottle usage & $\mathrm{n}=212$ & $\mathrm{n}=99$ & $\mathrm{n}=113$ & $\mathrm{n}=52$ & $\mathrm{n}=93$ & $\mathrm{n}=119$ \\
Present & $70.8 \%$ & $69.7 \%$ & $71.7 \%$ & $22.7 \pm 3.2$ & $68.8 \%$ & $72.3 \%$ \\
Absent & $29.2 \%$ & $30.3 \%$ & $28.3 \%$ & $22.7 \pm 4.8$ & $31.2 \%$ & $27.7 \%$ \\
\hline
\end{tabular}

*p<0.05

AGA: appropriate for gestational age, SGA: small for gestational age FGID: functional gastrointestinal disorders, c/s: cesarean section

The education level of the mother or family socioeconomic status was not related to FGID frequency ( $p=0.203$ and $p=0.185$, respectively). FGID was more frequent in exclusively breastfed infants $(54.8 \%$ vs $36.1 \%$, p<0.05) (Table I). Other demographic data, maternal, birth or feeding related variables were not related to FGID as given in Table I.

Regarding the FGID subgroups, infantile colic was seen mostly in girls $(68.6 \%$ vs. $31.4 \%$, $\mathrm{p}=0.016$ ). No difference was present with regard to gender in other subgroups. Infantile colic and dyschesia were more frequent $(2.4 \pm$ 1.0 vs. $4.3 \pm 2.2$ months, and $2.3 \pm 1.5$ vs. $4.2 \pm$ 2.1 months, respectively) in younger infants $(p<0.05)$. Regurgitation frequency was not different with regards to age. Variables related to birth such as the number of miscarriages, parity and birth weight did not have an effect on FGID subgroups. In the 4-6 week-old infants with infantile dyschesia, the delivery route was mostly C-section (83.3\% vs. $16.7 \%, \mathrm{p}=0.006)$. Similarly, regurgitation was more frequent in 6-7 month-old infants born by C-section $(88.9 \%$ vs. $11.1 \%$, $\mathrm{p}=0.035)$. Maternal education level or family type had no effect on FGID subgroups. Infantile dyschesia was less frequently $(17.5 \%)$ seen in families with intermediate SES ( $\mathrm{p}=0.044)$ in 4-6 week old infants. Type of first consumed food or starting time of breastfeeding did not have an effect on FGID subgroups. Regurgitation was more frequent in infants being exclusively breastfed compared to other types of feeding (breastfed $60.9 \%$, mixed $30.4 \%$, non-breastfed $8.7 \%, \mathrm{p}=0.037)$. Infants with regurgitation had less breastfeeding problems $(82.6 \%$ vs. $17.4 \%$, $\mathrm{p}=0.013$ ). Bottle/pacifier usage did not affect FGID subgroups either.

PPD was detected in $46.5 \%$ of the mothers. The rate of depression was not different between age groups or genders $(p=0.591, p=0.681)$. In mothers with depression quality of life scores were lower $(20.9 \pm 3.4$ vs. $23.9 \pm 3.6, p=0.003)$. Infantile colic was seen higher in the presence of depression, but this was not significant $(29.3 \%$ vs. $11.4 \%, p=0.057)$. Edinburg depression scale scores were higher in the presence of infantile colic as well (11.6 \pm 5.6 vs. $8.3 \pm 4.7, \mathrm{p}=0.015)$. (Table II). PPD was significantly lower in mothers with low education levels (illiterate and literate but 
Table II. Relation of FGID with postpartum depression and life quality.

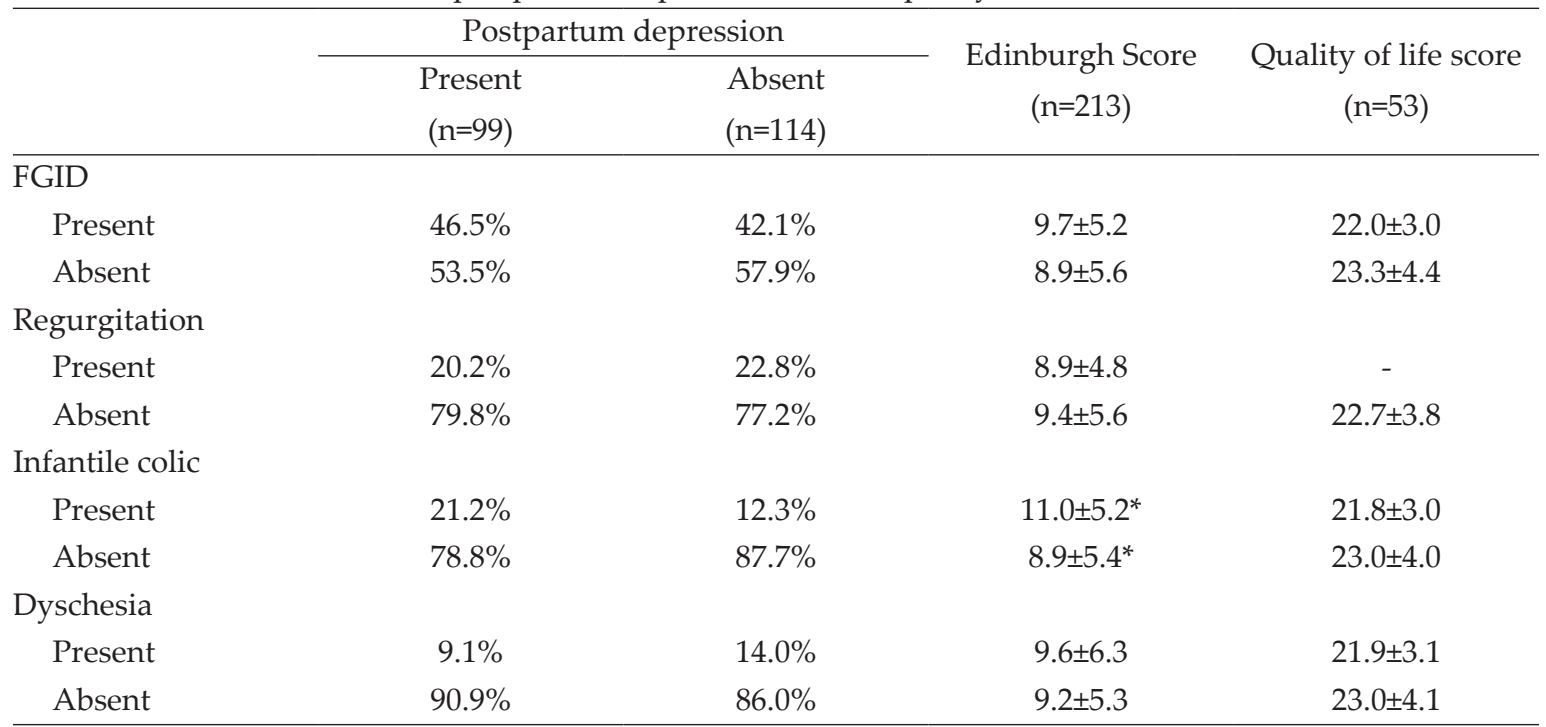

FGID: functional gastrointestinal disorder ${ }^{*} \mathrm{p}<0.05$

did not finish primary school) and in families with low SES ( $\mathrm{p}=0.046$ and 0.012 , respectively). Any other demographic data or variables related to the birth, mother or feeding were not related to PPD (Table I). The mean QoL score was $22.7 \pm 3.8$. The scores were not different with regards to FGID presence, demographic data, mother, birth or feeding variables (Table I and II).

\section{Discussion}

FGID's are chronic problems that affect the life of patients in many ways. There are also many factors like genetics, environment, life stress, psychological state, motility and gut hypersensitivity that may be related to these disorders. ${ }^{2}$ The effect of parent's psychological state and behavior are also emphasized., We found that FGID are common in infants; regurgitation, infantile colic and infantile dyschesia being the most common ones. Gender did not have an effect on FGID, except infantile colic. Infantile colic was mostly seen in girls, and it seems to be relevant to PPD.

In Izmir, which is the biggest city in the Aegean region, women are mostly elementary school graduates and the SES of the families is intermediate or high. ${ }^{30}$ SES and vital parameters of our study were similar to the Aegean region. Some birth parameters were better in our study group compared to Turkey, such as miscarriage and being small for gestational age. ${ }^{30}$ It is assumed that breastfeeding might take a role in FGID as it is a determinant of microbiota. ${ }^{31}$ Shorter duration of breastfeeding might cause multiple FGIDs. ${ }^{32}$ We found higher exclusive breastfeeding rates $(44.8 \%)$ compared to Turkish data. ${ }^{30}$ This may be due to our approach as a baby-friendly hospital. Additionally, Izmir is a baby-friendly province. Bottle-feeding was reported in $39.7 \%$ of the babies younger than 6 months. ${ }^{30}$ Bottle or pacifier usage was found in $70.8 \%$ of our study group. This rate may be higher due to pacifier usage. Using pacifiers is a factor increasing bottle usage. In time, this increases breast rejection and eventually bottlefeeding. ${ }^{33}$ Other data about feeding was similar to Turkish data. ${ }^{30}$

FGID is seen in $27.1 \%$ of infants/toddlers between 0-3 years old. It may be as high as $67-87 \%$ in $2-4$ months of age. ${ }^{21-24}$ Regurgitation $(25.9 \%)$, colic (5.9\%) and functional constipation $(4.7 \%)$ are the most common disorders. ${ }^{21}$ In 
our study group FGID rate was high (44.1\%). Regurgitation, infantile colic and dyschesia were the most frequent disorders with similar rates reported in a review as $17.3-26.0 \%, 6-19 \%$ and $2-5.6 \%$, respectively. ${ }^{34}$ Even though FGID frequency did not differ with regard to sex, infantile colic was mostly seen in girls in our study. No gender difference is reported for FGID or infantile colic in the literature. ${ }^{21,35}$

4-6 week-old infants with dyschesia and 6-7 month-old infants with regurgitation were mostly born by cesarean. This may be due to the microbiota differences between vaginal and cesarean delivery. The effect of delivery mode on infant microbiota is well defined..$^{32,36}$ It is also documented that microbiota is an important factor in the genesis of FGID. ${ }^{37}$ Breastfeeding may also have an impact on FGID by affecting microbiota. ${ }^{35}$ One study demonstrated the relation of a shorter duration of breastfeeding and the development of irritable bowel syndrome in adult life. ${ }^{37}$ We could not find any relation between FGID and feeding parameters. FGID, predominantly regurgitation, was more frequent in breastfed infants in our study which was contradictory to the literature. ${ }^{38,39}$ On the other hand, even regurgitation was higher in breastfed infants, infants with regurgitation had fewer breastfeeding problems. As proposed, infants with regurgitation should continue breastfeeding. ${ }^{38,39}$

PPD is a common disorder affecting almost 9.1-19.2\% of mothers. ${ }^{6,7}$ In our study we found a much higher frequency than reported earlier in Turkey, which was $23.8 \%{ }^{40}$ Many factors are known to affect the incidence. Even though the sex of the baby was not associated with PPD in our study, it is accepted as a factor by some authors. ${ }^{41}$ Socioeconomic factors such as low income are also associated with PPD. ${ }^{42}$ In our study group, PPD was lower in families with low SES. When analyzed further we saw that depression was less in mothers with a lower educational level. Higher education levels may raise awareness. We speculate that a raise in awareness may lead to an increase in anxiety, which is questioned in the Edinburgh
Depression Scale. ${ }^{28}$ This might explain lower depression rates in mothers with lower education levels. No other factor was found to influence PPD. Maternal depression was found to influence life quality as expected and has also been presented in previous studies. ${ }^{9,43}$

Regarding the FGID subgroups, infantile colic was related to PPD. This finding is in concordance with other studies. In the presence of infantile colic, PPD frequency is higher indicating an interaction. ${ }^{20}$ Behavioral symptoms like depression and anxiety of the mother might cause infantile colic and infantile colic might affect parents negatively leading to maternal depression. ${ }^{3,10}$ Depressed mothers may have a lower interaction with their infants and they might not respond to their infants' needs appropriately. When the needs of the infants were not met they may respond by crying to this distress. This may increase the occurrence of infantile colic. ${ }^{10}$ In the biopsychosocial model, life stress, psychological state and coping, are some factors that interact with symptoms. As suggested in this model, the psychological state of the baby may influence FGID. ${ }^{2}$ PPD was not related to any other FGID subgroup.

Giving birth to a child might cause some physical and psychological changes in mothers' lives. These changes lead to changes in life quality. ${ }^{9}$ In our study, QoL scores were 22.7 \pm 3.8 . The scores are expected between 0-30 on the scale we used. Therefore, scores in our study are not low. On the other hand, QoL scores were lower in depressed mothers with babies 4-6 weeks-old. This result supports the negative effect of PPD on life quality as discussed above. ${ }^{9,43}$ However, the life quality of the mothers did not affect or was not affected by the presence of FGID and subtypes in 4-6 week old infants. There is only one study evaluating the life quality of infants with FGID. This study revealed that FGID, especially if there is more than one, lowers life quality of the infant. ${ }^{32}$ However, the effect of FGID on mothers' life quality is still not known. Therefore, more studies are needed to evaluate the relation of life quality and FGID, especially in different age groups. 
There are some limitations to our study. First of all, our sample was selected from patients admitted to a tertiary level hospital. The SES of the families was above the average in Izmir. Since the sample was not population based, it may have a weakness in representing the population. Secondly, all data was obtained by questionnaires. However, we tried to minimize this limitation by questioning face to face. However, this still might lead to recall bias especially concerning feeding data of the older babies.

In conclusion, FGID (especially regurgitation, infantile colic and infantile dyschesia) and PPD are common problems in early infancy. From the FGID, infantile colic was related to PPD. Another influential factor on some FGID subgroups was C-Section delivery and breastfeeding in our study group. No other factor seems to affect FGID. Environment, life stress, parent's psychological state are some factors suggested to being responsible for the pathogenesis of FGID in older children. However, we suppose that other factors may be responsible for FGID in infancy. More studies are needed to enlighten this issue.

\section{Author contribution}

The authors confirm contribution to the paper as follows: study conception and design: Özlem Bekem, ìlker Günay, data collection: Özlem Bekem, İlker Günay, Filiz Çelik, Hurşit Apa; analysis and interpretation of results: Özlem Bekem, İlker Günay; draft manuscript preparation: Özlem Bekem, İlker Günay, Hurşit Apa.

All authors reviewed the results and approved the final version of the manuscript.

\section{Ethics approval}

Approval was obtained from the ethics committee of Dr. Behcet Uz Children's Ethic Committee (B-10-4-ISM-4-35-65-72, 28.02.2013). The procedures used in this study adhere to the tenets of the Declaration of Helsinki.

\section{Source of funding}

None declared.

\section{Conflicts of Interest}

The authors declare that they have no conflict of interest.

\section{REFERENCES}

1. Hyman PE, Milla PJ, Benninga MA, Davidson GP, Fleisher DF, Taminiau J. Childhood functional gastrointestinal disorders: neonate/toddler. Gastroenterolgy 2006; 130: 1519-1526.

2. Drossman DA, Creed FH, Olden KW, Svedlund J, Toner BB, Whitehead WE. Psychosocial aspects of the functional gastrointestinal disorders. Gut 1999; 45(Suppl 2): 1125-1130.

3. Hommel KA, McGraw KL, Ammerman RT, et al. Psychosocial functioning in children and adolescents with gastrointestinal complaints and disorders. J Clin Psychol Med Settings 2010; 17: 159-166.

4. van Tilburg MA, Levy RL, Walker LS, et al. Psychosocial mechanisms for the transmission of somatic symptoms from parents to children. World J Gastroenterol 2015; 21: 5532-5541.

5. Brummelte S, Galea LA. Postpartum depression: etiology, treatment and consequences for maternal care. Horm Behav 2016; 77: 153-166.

6. Serhan N, Ege E, Ayranc1 U, Kosgeroglu N. Prevalence of postpartum depression in mothers and fathers and its correlates. J Clin Nurs 2013; 22: 279-284.

7. Gavin NI, Gaynes BN, Lohr KN, Meltzer-Brody S, Gartlehner G, Swinson T. Perinatal depression: a systematic review of prevalence and incidence. Obstet Gynecol 2005; 106(5 Pt 1): 1071-1083.

8. Howell EA, Mora P, Leventhal H. Correlates of early postpartum depressive symptoms. Matern Child Health J 2006; 10: 149-157.

9. Sadat Z, Abedzadeh-Kalahroudi M, Atrian MK, Karimian Z, Sooki Z. The impact of postpartum depression on quality of life in women after child's birth. Iran Red Crescent Med J 2014; 16: e14995.

10. Akman I, Kuşçu K, Ozdemir N, et al. Mothers' postpartum psychological adjustment and infantile colic. Arch Dis Child 2006; 91: 417-419.

11. Kaymaz N, Yıldırım Ş, Topaloğlu N, et al. Prenatal maternal risk factors for infantile colic. Nurs Child Young People 2015; 27: 32-38. 
12. Vik T, Grote V, Escribano J, et al; European Childhood Obesity Trial Study Group. Infantile colic, prolonged crying and maternal postnatal depression. Acta Paediatr 2009; 98: 1344-1348.

13. Radesky JS, Zuckerman B, Silverstein M, et al. Inconsolable infant crying and maternal postpartum depressive symptoms. Pediatr 2013; 131: e1857-e1864.

14. Oświęcimska J, Szymlak A, Roczniak W, GirczysPołedniok K, Kwiecień. New insights into the pathogenesis and treatment of irritable bowel syndrome. Adv Med Sci 2017; 62: 17-30.

15. Carlson MJ, Moore CE, Tsai CM, Shulman RJ, Chumpitazi BP. Child and parent perceived foodinduced gastrointestinal symptoms and quality of life in children with functional gastrointestinal disorders. J Acad Nutr Diet 2014; 114: 403-413.

16. Chumpitazi BP. Update on dietary management of childhood functional abdominal pain disorders. Gastroenterol Clin North Am 2018; 47: 715-726.

17. Cohen Engler A, Hadash A, Shehadeh N, Pillar G. Breastfeeding may improve nocturnal sleep and reduce infantile colic: potential role of breast milk melatonin. Eur J Pediatr 2012; 171: 729-732.

18. Yalçın SS, Kuşkonmaz BB. Relationship of lower breastfeeding score and problems in infancy. Breastfeed Med 2011; 6: 205-208.

19. Varni JW, Bendo CB, Nurko S, et al; Pediatric Quality of Life Inventory (PedsQL) Gastrointestinal Symptoms Module Testing Study Consortium. Health-related quality of life in pediatric patients with functional and organic gastrointestinal diseases. J Pediatr 2015; 166: 85-90.

20. Abacı FB, Gökçe S, Tuygun N, Karacan CD, Öner Ö. Psychosocial status and quality of life in mothers of infants with colic. Turk J Pediatr 2013; 55: 391-395.

21. van Tilburg MA, Hyman PE, Walker L, et al. Prevalence of functional gastrointestinal disorders in infants and toddlers. J Pediatr 2015; 166: 684-689.

22. Osatakul S, Sriplung H, Puetpaiboon A, Junjana CO, Chamnongpakdi S. Prevalence and natural course of gastroesophageal reflux symptoms: a 1-year cohort study in Thai infants. J Pediatr Gastroenterol Nutr 2002; 34: 63-67.

23. Nelson SP, Chen EH, Syniar GM, Christoffel KK. Prevalence of symptoms of gastroesophageal reflux during infancy. A pediatric practice-besed survey. Pediatric Practice Research Group. Arch Pediatr Adolesc Med 1997; 151: 569-572.

24. Hegar B, Dewanti NR, Kadim M, Alatas S, Firmansyah A, Vandenplas Y. Natural evolution of regurgitation in healthy infants. Acta Paediatr 2009; 98: 1189-1193.
25. Altuntuğ K, Ege E. Doğum sonu yaşam kalitesi ölçeğinin Türkçe uyarlamasının geçerlik ve güvenirliği. Anadolu Hemşirelik ve Sağlık Bilimleri Dergisi 2012; 15: 214-222.

26. Andrews-Fike C. A review of postpartum depression. Prim Care Companion J Clin Psychiatry 1999; 1: 9-14.

27. Nesanır N, Eser E. Türkiye'de sağlık alanında kullanılmak üzere bir sosyoekonomik indeks denemesi. TAF Prev Med Bull 2010; 9: 277-288.

28. Engindeniz AN, Küey L, Kültür S. Edinburgh doğum sonrası depresyon ölçeği Türkçe formu geçerlilik ve güvenilirlik çalışması. Bahar Sempozyumları 1996; 1: $51-52$

29. Cox JL, Holden JM, Sagovsky R. Detection of postnatal depression. Development of the 10item Edinburgh Postnatal Depression Scale. Br J Psychiatry 1987; 150: 782-786.

30. Hacettepe Üniversitesi Nüfus Etütleri Enstitüsü. 2013 Türkiye Nüfus ve Sağlık Araştırması. Hacettepe Üniversitesi Nüfus Etütleri Enstitüsü, T.C. Kalkınma Bakanlığı ve TÜBİTAK, Ankara, Türkiye. Web adresi: http://www.hips.hacettepe.edu.tr/tnsa2013/ (Erişim tarihi: 26.12.2019).

31. Saavedra JM, Dattilo AM. Early development of intestinal microbiota: implications for future health. Gastroenterol Clin North Am 2012; 41: 717-731.

32. Bellaiche M, Oozeer R, Gerardi-Temporel G, Faure C, Vandenplas Y. Multiple functional gastrointestinal disorders are frequent in formula-fed infants and decrease their quality of life. Acta Paediatr 2018; 107: 1276-1282.

33. Zimmerman E, Thompson K. Clarifying nipple confusion. J Perinatol 2015; 35: 895-899.

34. Vandenplas Y, Abkari A, Bellaiche M, et al. Prevalence and health outcomes of functional gastrointestinal symptoms in infants from birth to 12 months of age. J Pediatr Gastroenterol Nutr 2015; 61: 531-537.

35. Lucassen PL, Assendelft WJ, van Eijk JT, Gubbels JW, Douwes AC, van Geldrop WJ. Systematic review of the occurrence of infantile colic in the community. Arch Dis Child 2001; 84: 398-403.

36. Madan JC, Farzan SF, Hibberd PL, Karagas MR. Normal neonatal microbiome variation in relation to environmental factors, infection and allergy. Curr Opin Pediatr 2012; 24: 753-759.

37. De Palma G, Collins SM, Bercik P. The microbiotagut-brain axis in functional gastrointestinal disorders. Gut Microbes 2014; 5: 419-429. 
38. Salvatore S, Abkari A, Cai W, et al. Review shows that parental reassurance and nutritional advice help to optimise the management of functional gastrointestinal disorders in infants. Acta Paediatr 2018; 107: 1512-1520.

39. Hegar B, Dewanti NR, Kadim M, Alatas S, Firmansyah A, Vandenplas Y. Natural evolution of regurgitation in healthy infants. Acta Paediatr 2009; 98: 1189-1193.

40. Özcan NK, Boyacıoğlu NE, Dinç H. Postpartum Depression Prevalence and risk factors in Turkey: a systematic review and meta-analysis. Arch Psychiatr Nurs 2017; 31: 420-428.
41. Hassanein IM, Fathalla MM, Abdel Rahim T. The role of newborn gender in postpartum depressive symptoms among women in Upper Egypt. Int J Gynaecol Obstet 2014; 125: 138-140.

42. O'Hara MW, Swain AM. Rates and risk of postpartum depression: a meta-analysis. Int Rev Psychiatry 1996; 8: 37-54.

43. Papamarkou M, Sarafis P, Kaite CP, Malliarou M, Tsounis A, Niakas D. Investigation of the association between quality of life and depressive symptoms during postpartum period: a correlational study. BMC Womens Health 2017; 17: 115. 